\title{
Artificial ground freezing of a volcanic ash: laboratory tests and modelling
}

1 Francesca Casini PhD

Research Assistant, Dipartimento di Ingegneria Civile e Ingegneria Informatica, DICII, Università degli Studi di Roma Tor Vergata, Roma, Italy

2 Antonio Gens PhD

Professor, Departamento de Ingeniería del Terreno, Cartográfica y Geofísica, Universitat Politecnica de Catalunya, Barcelona, Spain
3 Sebastia Olivella PhD

Professor, Departamento de Ingeniería del Terreno, Cartográfica y Geofísica, Universitat Politecnica de Catalunya, Barcelona, Spain

4 Giulia M. B. Viggiani PhD

Professor, Dipartimento di Ingegneria Civile e Ingegneria Informatica, Università di Roma Tor Vergata, Roma, Italy
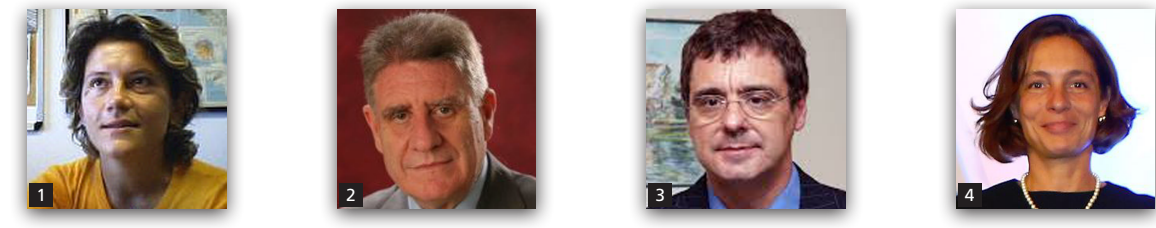

The use of artificial ground freezing (AGF) to form earth support systems has had applications worldwide. These cover a variety of construction problems, including the formation of frozen earth walls to support deep excavations, structural underpinning for foundation improvement and temporary control of ground water in construction processes. On one hand, the main advantage of AGF as a temporary support system in comparison to other support methods, such as those based on injections of chemical or cement grout into the soil, is the low impact on the surrounding environment as the refrigerating medium required to obtain AGF is circulated in pipes and exhausted in the atmosphere or re-circulated without contamination of the ground water. On the other hand, the available methods may vary significantly in their sustainability and complexity in terms of times and costs required for their installation and maintenance. The ability to predict the effects induced by AGF on granular materials is therefore crucial to assessing construction time and cost and to optimising the method. In this work, the thermo-hydro-mechanical processes induced by artificial freezing of a soil body are studied using a constitutive model that encompasses frozen and unfrozen behaviour within a unified effective-stress-based framework. It makes use of a combination of ice pressure, liquid water pressure and total stress as state variables. The model is validated and calibrated using the results of a series of laboratory tests on natural samples of a volcanic ash (Pozzolana) retrieved during construction of Napoli underground, where the technique of AGF was used extensively to stabilise temporarily the ground and control the ground water.

\section{Notation}

C intercept of strength envelope with $q$ axis

$C_{\mathrm{p}} \quad$ intercept of peak strength envelope with $q$ axis

$c_{\mathrm{p}}{ }^{\prime} \quad$ cohesion of peak strength envelope

$d_{50} \quad$ mean diameter

$F$ yield function

$F_{0} \quad$ normalising constant dimensions of stress

$k$ material constant

$k_{\mathrm{i}} \quad$ permeability of soil containing ice

$k_{\mathrm{r}} \quad$ relative permeability

$k_{\text {sat }} \quad$ permeability of fully saturated unfrozen soil

$k_{\mathrm{t}} \quad$ thermal conductivity of soil

$k_{\mathrm{ti}} \quad$ thermal conductivity of ice

$k_{\mathrm{tl}} \quad$ thermal conductivity of liquid water

$k_{\mathrm{ts}} \quad$ thermal conductivity of soil mineral specific latent heat of fusion of water slope of strength envelope material constant in freezing retention model slope of peak strength envelope material constant, exponent of flow function ice pressure entry value mean total stress mean effective stress air entry value material constant initial confining mean total stress initial mean effective stress

ice pressure

liquid water pressure

mean net stress 
$p_{\text {no }} \quad$ saturated pre-consolidation pressure

$p_{\text {no }}(\mathrm{s})$ pre-consolidation pressure with suction

$p_{\mathrm{s}} \quad$ mean net stress

$p_{\mathrm{s} 0} \quad$ mean net stress

$p_{\text {wo }} \quad$ initial pore water pressure

$q \quad$ deviatoric stress

$q_{\mathrm{p}} \quad$ deviatoric stress at peak

$r \quad$ material constant

$s$ suction

$S_{1} \quad$ degree of saturation of liquid water

$T$ temperature

$t$ time

$U$ coefficient of uniformity

$u$ back pressure

$v_{\mathrm{p}} \quad$ axial displacement rate

$V_{\mathrm{v}} \quad$ volume of voids

$V_{\text {w }} \quad$ volume of water

$\beta \quad$ material constant

$\Gamma \quad$ fluidity parameter

$\Gamma_{0} \quad$ fluidity parameter at suction zero

$\Delta T$ temperature ramp loading

$\Delta x \quad$ increment $x$ direction

$\delta \quad$ material constant

$\dot{\varepsilon} \quad$ total strain rate

$\varepsilon_{\mathrm{a}} \quad$ axial strain

$\varepsilon_{\mathrm{s}} \quad$ deviatoric strain

$\dot{\varepsilon}^{\mathrm{e}} \quad$ elastic strain rate

$\dot{\varepsilon}^{\mathrm{vp}} \quad$ visco-plastic strain rate

$\kappa(\mathrm{s}) \quad$ slope of unloading-reloading line with suction

$\lambda(0)$ slope of unfrozen water saturated normal compression line

$\lambda(\mathrm{s}) \quad$ slope of normal compression line with suction

$\rho_{\mathrm{i}} \quad$ mass density of the frozen water

$\rho_{1} \quad$ mass density of the liquid water

$\sigma_{\mathrm{ij}} \quad$ total stress

$\sigma_{\mathrm{ij}, \mathrm{n}} \quad$ net stress

$\sigma_{\text {la }} \quad$ liquid/air surface tension

$\sigma_{\mathrm{li}} \quad$ liquid/ice surface tension

$\sigma_{\mathrm{x}} \quad$ total stress $x$ direction

$\sigma_{\mathrm{y}} \quad$ total stress $y$ direction

$\Phi$ flow function

$\varphi_{\mathrm{p}}{ }^{\prime} \quad$ peak friction angle

\section{Introduction}

Frozen ground is soil or rock with a temperature below the freezing point of water $\left(0^{\circ} \mathrm{C}\right)$. The definition is based entirely on temperature and is independent of the water and ice content of the soil or rock (Andersland and Landanyi, 2004). The two main effects of an increasing ice content in the soil as the temperature decreases are (i) the increase of soil strength and (ii) the decrease of permeability, which makes the frozen soil impervious to water seepage.

Natural freezing occurs seasonally in many areas of the globe and can adversely affect the engineering performance of roads and pavements as ice lenses form and grow. Several features are associated with perennially frozen ground, such as ice-wedge and thermokarst topography. Engineering considerations require an understanding of the natural freezing process, of the effects of thawing frozen ground, of seasonal frost heave and settlement and of how useful aspects of frozen ground, such as high strength and water tightness, can be used expediently for construction purposes (Andersland and Landany, 2004).

In contrast to natural freezing, man-made or artificial ground freezing (AGF) is a controllable process and can be used profitably by civil and mining engineers to temporarily provide structural support and/or to exclude groundwater from an excavation until construction of the final lining provides permanent stability and water tightness. The process was originally applied mainly to vertical openings, such as shafts and pits, but also to other excavation works, such as tunnels, which were considered with the increasing ability to drill and install freezing tubes horizontally. Besides protecting excavations, AGF has also been used to stabilise slopes, to retrieve undisturbed samples of coarse grained soils, to construct temporary access roads and to maintain permafrost below overhead pipeline foundations and heated buildings (Harris, 1995). Recently, AGF has been considered as a possible solution to radioactive contamination of the water surrounding the compromised Fukushima nuclear power plant (www.groundfreezing.net/projects/ ground-freezing-fukushima).

AGF is one of the construction techniques that were adopted extensively during construction of Line 1 of Napoli underground. It was used to ensure stability and waterproofing of the platform tunnels and inclined passageways during excavation below the ground water table through loose granular soils of pyroclastic origin (Pozzolana) and a fractured soft rock (Neapolitan Yellow Tuff) (Cavuoto et al., 2011; Russo et al., 2012; Viggiani and de Sanctis, 2009).

In this case, AGF was carried out by driving freeze tubes into the ground parallel to the tunnel length around the future excavation section and then circulating a refrigerating fluid into the tubes until the temperature of the ground around them was below the freezing point of water. Freezing was activated with nitrogen and maintained with brine. The contractor specified that excavation should be undertaken once a 1-m-thick frozen collar was formed around the tunnel section. This was conventionally defined as the area of the soil at a temperature below $-10^{\circ} \mathrm{C}$. The growth of the frozen body was monitored with temperature sensors located along chains parallel to the freeze pipes. Due to the complexity of the works, the construction of the line was accompanied by an intense programme of monitoring designed to measure and/ or control the effects of construction on adjacent structures and, for the extension and completeness of the monitoring, represented a unique opportunity to collect field data on the performance of AGF.

Several authors have attempted to back analyse and interpret different aspects of the freezing process. Viggiani and de Sanctis 
(2009) analysed transient heat propagation numerically using the finite-element code ABAQUS. The thermal properties of the soil were obtained by back analysis of an instrumented trial field in which the ground temperature around the freezing holes was measured during cycles of freezing and thawing. An attempt to predict ground heave on freezing and subsequent settlements on thawing with a decoupled approach was also carried out by finiteelement analyses imposing freezing-induced volume strains to the ground (De Santis, 2006).

Colombo (2010) also tackled the problem of heat propagation, comparing the results of theoretical analyses by Sanger and Sayles (1979) and those obtained by finite-element analyses. In this case, the thermal properties of the ground were assigned based on literature data. Both analytical and finite-element approaches were adopted to analyse realistic layouts of freezing tubes similar to those used during construction of Napoli underground, and the results were compared with the experimental data.

Papakonstantinou et al. (2012) examined the temperature monitored within the ground during the freezing process numerically and took into account the thermo-hydraulic coupling. The influence of a number of parameters, including the spacing between the freeze pipes and the thermal conductivity of the ground, was investigated to gain an understanding of the thermal behaviour of the ground during activation of artificial freezing with nitrogen.

The thermo-hydro-mechanical (THM) processes induced by freezing and thawing of pore fluid within soils are complex and can have significant mutual interaction (Nishimura et al., 2009). As the temperature decreases, the ice content of the soil increases; the ice becomes a bonding agent between soil particles or blocks of rock, increasing the strength of the soil/rock mass and modifying the pore water pressures and the effective stress on the soil skeleton, which, in turn, induces mechanical deformation. At the same time, any changes in the hydraulic and mechanical boundary conditions can affect the thermal processes by advection and changes of ice and water contents (Gens, 2010).

Zhou and Meschke (2013) proposed a three-phase model considering solid particles, liquid water and crystal ice as separate phases and mixture temperature, liquid pressure and solid displacement as the primary field variables. Although the model was developed within the framework of linear poro-elasticity and further developments are required, it was able to capture various couplings among the phase transition, the liquid transport within the pore space and the accompanying mechanical deformation, and was validated by means of selected analyses, including AGF for temporary support during tunnelling.

This paper presents preliminary results obtained using a full THM model (Nishimura et al., 2009), which was calibrated against experimental data obtained under temperature-controlled tests on a volcanic ash (Pozzolana) retrieved from the subsoil in Municipio Station. The testing programme was carried out by Tecno-in SpA (www.tecnoin.it/en) as part of the geotechnical investigation for the works of Napoli underground (Cantone et al., 2006). The data were kindly made available to the authors in the context of a research project bringing together constitutive modelling, laboratory tests and field data. The project was carried out in cooperation between UPC Barcelona, Università di Roma Tor Vergata and technical personnel and engineers involved in the design and construction of Napoli underground (Casini et al., 2013). The final goal of the research is to study the freezing process considering the full THM coupling and model reliably the construction process for confident design of other similar works.

\section{Constitutive model adopted}

The THM formulation for low-temperature problems in watersaturated soils has been developed by Nishimura et al. (2009) based on the THM model originally developed by Olivella et al. (1994, 1996) and Gens et al. (1998) for high-temperature problems involving a gas phase. In this case, the gas phase is replaced by a second solid phase representing ice. The formulation has been implemented in CODE_BRIGHT (Olivella et al., 1996) using a visco-plastic version of the model (Molist, 1997; Sanchez, 1997), based on the general theory of Perzyna (1986) and Desai and Zhang (1987), mainly to regularise integration of the elastoplastic material law on softening. In the constitutive model, the governing equations were developed from fundamental physical requirements, taking into account the interactions between thermal, hydraulic and mechanical processes in frozen soils. The formulation includes a critical state constitutive model that adopts net stress and suction as stress variables, which reduces to an effective stress-based model similar to modified cam-clay under unfrozen conditions. The validation and calibration of the model are presented below.

\section{Freezing retention model}

The mechanisms linking the change in volume of the liquid phase relative to that of the ice phase must be defined as a function of the thermodynamic properties of water. A liquid ice surface tension $\sigma_{\mathrm{li}}$ develops at the interface between the two phases as the temperature decreases. This tension must be balanced by the difference of pressure in frozen and liquid water $P_{\mathrm{i}}$ and $P_{1}$. Thermodynamic equilibrium between the two phases is described by the ClausiusClayperon equation, reported below its integrated form using $273 \cdot 15 \mathrm{~K}$ as the reference temperature

$$
\text { 1. } P_{\mathrm{i}}=\frac{\rho_{\mathrm{i}}}{\rho_{1}} P_{1}-\rho_{\mathrm{i}} \ln \left(\frac{T}{273 \cdot 15}\right)
$$

where $l(=333.5 \mathrm{~kJ} / \mathrm{kg})$ is the specific latent heat of fusion of water, $\rho_{\mathrm{i}}$ and $\rho_{\mathrm{l}}$ are the mass densities of the frozen and liquid water respectively. The van Genuchten (1980) equation is used to represent the freezing retention model, expressing the link between the degree of saturation of liquid (unfrozen) water $S_{1}$ and the difference between the pressures of ice $P_{\mathrm{i}}$ and liquid water $P_{1}$ 
2.

$$
S_{\mathrm{I}}=\left[1+\left(\frac{P_{\mathrm{i}}+P_{\mathrm{I}}}{P}\right)^{\frac{1}{1-m}}\right]^{-m}
$$

where $m$ is a material constant, and $P$ is the ice pressure entry value. Suction $s=P_{\mathrm{i}}-P_{1}$ depends on temperature $T$ and liquid pressure $P_{1}$ as

3.

$$
s=P_{\mathrm{i}}-P_{\mathrm{I}}=\left(\frac{\rho_{\mathrm{i}}}{\rho_{\mathrm{I}}}-1\right) P_{\mathrm{I}}-\rho_{\mathrm{i}} \ln \left(\frac{T}{273 \cdot 15}\right)
$$

Substituting Equation 3 into Equation 2, it is possible to obtain the relationship between $S_{1}$ and $T$.

Finally, the relative permeability $k_{\mathrm{r}}$ representing the ratio between the permeability of the soil containing ice $\left(S_{1} \leq 1\right) k$ and the permeability of fully saturated unfrozen soil $\left(S_{1}=1\right) k_{\text {sat }}$ is obtained from Equation 2, considering the link between the relative permeability and the degree of saturation of the liquid phase (Mualem, 1976; van Genuchten, 1980)

4.

$$
k_{\mathrm{r}}=\frac{k}{k_{\text {sat }}}=\sqrt{S_{1}}\left[1-\left(1-S_{1}^{1 / m}\right)^{m}\right]
$$

\section{Mechanical model}

The Barcelona Basic Model (BBM; Alonso et al., 1990) was extended to frozen soils with a two-stress variable constitutive relationship (Nishimura et al., 2009) making use of net stress

$$
\text { 5. } \sigma_{\mathrm{ij}, \mathrm{n}}=\sigma_{\mathrm{ij}}-\max \left(P_{1}, P_{\mathrm{i}}\right)
$$

representing external confinement and suction

6. $s=\max \left(P_{\mathrm{i}}-P_{1}, 0\right)$

The yield function is given by

7. $q^{2}=M^{2} \cdot\left[p_{\mathrm{n}}+p_{\mathrm{s}}(s)\right] \cdot\left[p_{\mathrm{c}}(s)-p_{\mathrm{n}}\right]$

in which $q$ is the deviatoric stress, $p_{\mathrm{n}}$ is the mean net stress, $p_{\mathrm{c}}$ and $p_{\mathrm{s}}$ are the intersections of the yield surface with the isotropic axis, defining its current size (see Figure 1), and $M$ is a material constant.

The evolution of the pre-consolidation pressure $p_{\mathrm{c}}$ with suction is given by the so-called loading-collapse curve (LC)

8.

$$
p_{\mathrm{c}}(s)=p^{*}\left(\frac{p_{\mathrm{c} 0}}{p^{*}}\right)^{\frac{\lambda(0)-\kappa}{\lambda-\kappa}}
$$
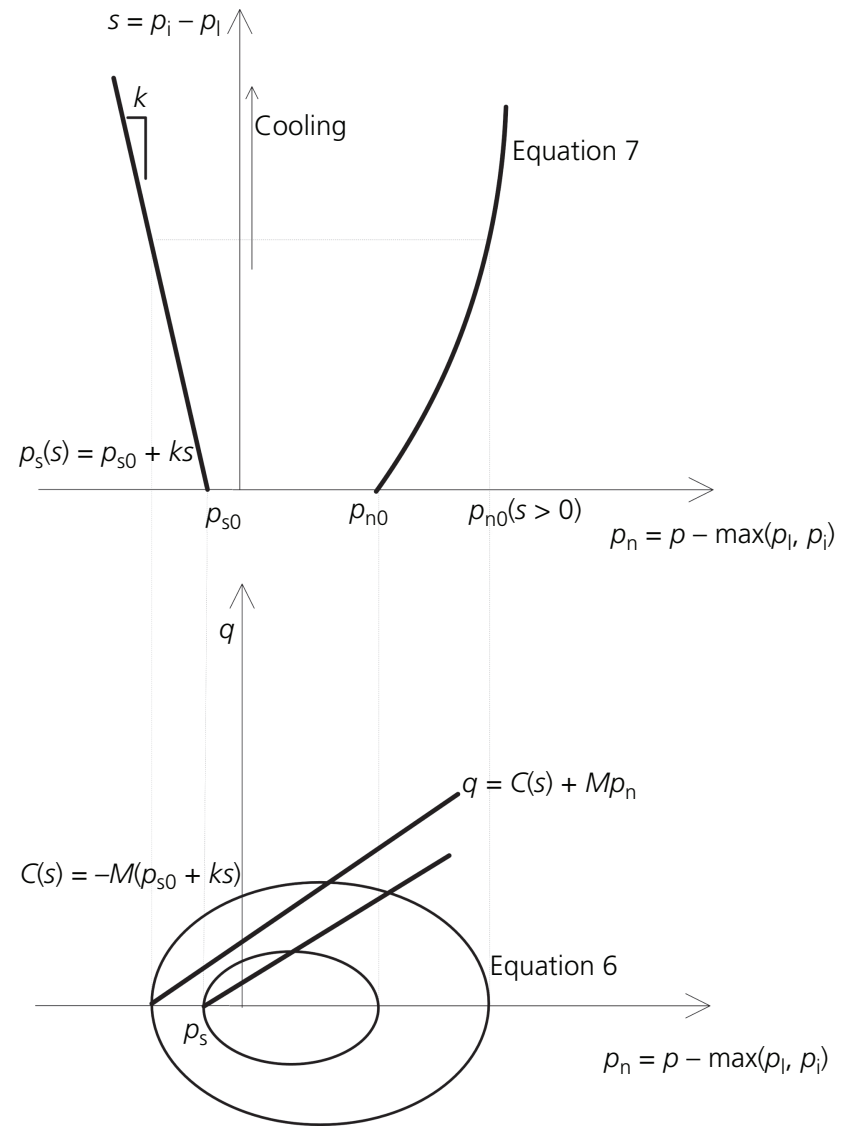

Figure 1. Qualitative predictions of constitutive model on temperature decrease

where

$$
\text { 9. } \lambda=\lambda(0) \cdot[(1-r) \exp (-\beta s)+r]
$$

and $\lambda(0), \kappa, p^{*}, \beta$ and $r$ are all material constants, while $p_{\mathrm{s}}$ depends linearly on suction

10. $p_{\mathrm{s}}=k s+p_{\mathrm{s} 0}$

and $k$ is a material constant.

To extend the elastic domain to low effective stress and for negative effective stress, a minimum value of the bulk modulus $K=(1+e) p^{\prime} / \kappa$ is defined below which the bulk modulus is constant and equal to $K_{\text {min }}$, a user-defined value. The volumetric strains are calculated by integrating the following equation: $\frac{d e}{1+e}=a_{1} \frac{d p^{\prime}}{p^{\prime}}+a_{2} \frac{d s}{s+0 \cdot 1}$, where $a_{1}=-\frac{\kappa}{1+e}$ and $a_{2}=-\frac{\kappa_{\mathrm{s}}}{1+e}(0 \cdot 1 \mathrm{MPa}$ represents the atmospheric pressure) with $K=a_{1} p^{\prime}$ and $p_{\text {min }}^{\prime}=K_{\min } / a_{1}$. In the simulations, we defined $K_{\min }=0 \cdot 1 \mathrm{MPa}$. 
The model predicts that a temperature decrease induces a suction increase that, in turn, produces an increase of the preconsolidation stress, Equations 8 and 9, and of the strength of the soil, as shown schematically in Figure 1. An important role is played by the increase in strength due to the increased size of the yield surface as suction increases. As $p_{\mathrm{s}}$ increases with increasing suction (decreasing temperature), the intercept (with the $q$ axis) $C$ increases, which represents a sort of apparent cohesion. This means that a larger negative net stress than that related to true cohesion of the material in saturated condition $p_{\mathrm{s} 0}$ becomes possible due to the increase of suction on cooling. For further details, the reader is referred to Alonso et al. (1990), Nishimura et al. (2009) and Gens (2010).

\section{Visco-plastic formulation}

The preceding set of constitutive relations was implemented in the visco-plastic form proposed by Perzyna (1986). The total strain rate $\dot{\varepsilon}$ is the sum of the elastic and visco-plastic strain rate

11. $\dot{\varepsilon}=\dot{\varepsilon}^{\mathrm{e}}+\dot{\varepsilon}^{\mathrm{vp}}$

The visco-plastic strain rate is expressed as

12. $\dot{\varepsilon}^{\mathrm{vp}}=\Gamma\langle\Phi(F)\rangle \frac{\partial F}{\partial \sigma}$

where $\Gamma$ is referred to as the fluidity parameter, with units of inverse of time, and denotes the relative rate of visco-plastic strain. The scalar flow function $\Phi$ increases monotonically with $F$ and defines the current magnitude of the visco-plastic strain rate; this is expressed with argument $F$, which is the yield function with associative plasticity. The adopted form of the flow function is

13.

$$
\Phi(F)=\left(\frac{F}{F_{0}}\right)^{N}
$$

where exponent $N$ is a material parameter, in this case assumed to be 3, based on literature data (Morgenstern et al., 1980; Sayles, 1968), and $F_{0}$ is a normalising constant with the same units as that of $F$, in this case $1 \mathrm{MPa}$.

Although visco-plasticity was implemented with the main aim of regularising integration of the elasto-plastic material law on softening (Conti et al., 2013; Wang et al., 1997; Zienkiewicz and Taylor, 2000), this can be useful to model the behaviour of frozen soils and its dependency on temperature (Andersland and Ladanyi, 2004) by introducing the dependency of fluidity on suction (Alonso et al., 2005), $\Gamma=\Gamma_{0} \exp (\sigma s)$. In this work, however, due to the lack of experimental data to calibrate the model adequately, the dependency of fluidity on suction has been neglected with a constant value of $\Gamma=\Gamma_{0}=10^{-7} \mathrm{~s}^{-1}$ and $\delta=0$ (see Table 4).

\section{Experimental work}

\section{Material and methods}

The material used for the experimental programme is a volcanic ash retrieved from two sites in Napoli, corresponding to Municipio and Toledo Stations of Line 1 of Napoli underground (www. studiocavuoto.com). Pyroclastic flow deposits, or Pozzolanas, were put in place about 12000 years ago during the second active phase of the nearby volcanic complex of the Phlegrean Fields. This active phase was followed by a rest period of about 2000 years, during which the pyroclastic materials were eroded, transported and re-deposited. The remoulded Pozzolanas are very well graded and not easily recognised from the intact pyroclastic deposits. They appear layered, sometimes inter-bedded with in situ Pozzolanas, sometimes with marine sand deposits, such as in the area of Municipio Station (Viggiani and de Sanctis, 2009).

Figure 2 shows the soil profiles at the locations where the samples were retrieved, down to $30 \mathrm{~m}$ below ground level (b.g.l.). In both cases, the subsoil consists essentially of made ground (matrix of pyroclastic sand incorporating fragments of rubble and Neapolitan tuff and remoulded ash) and alluvial and/or in situ pyroclastic sand (Pozzolana) over the Neapolitan Yellow Tuff. At Piazza Municipio, the made ground is around $9 \mathrm{~m}$ thick, below which a layer of remoulded ash mixed with marine sand is found between $2 \cdot 1$ and $-1.9 \mathrm{~m}$ a.s.1., indicating a shallow-marine depositional environment. At greater depths and down to about $-10 \cdot 5 \mathrm{~m}$ above sea level (a.s.1.) there is remoulded Pozzolana. The thickness of the remoulded Pozzolana above the formation of Neapolitan Yellow Tuff is about $8.6 \mathrm{~m}$, while the total thickness of the cohesionless granular materials over the Neapolitan Yellow Tuff amounts to about $21 \mathrm{~m}$. At Toledo, the made ground is $3.4 \mathrm{~m}$ thick; below a relatively thin $(3.4 \mathrm{~m})$ layer of paleosol, remoulded volcanic ash is found down to $20.8 \mathrm{~m}$ b.g.l. and then Pozzolana, for a total thickness of cohesionless granular materials over the Neapolitan Yellow Tuff of about $34 \mathrm{~m}$.

At both sites, undisturbed samples of volcanic ashes were retrieved at depths of about 10 to $11 \mathrm{~m}$ b.g.l.; at Municipio, this is below the groundwater table (at about $8.5 \mathrm{~m}$ b.g.l.) and therefore the samples were fully saturated, while at Toledo the volcanic ashes are above the groundwater table (at about $21 \mathrm{~m}$ b.g.l.) and therefore only partly saturated. Table 1 summarises the values of the average physical properties of the tested material. Values of voids ratio and inter-particle porosity are within the range quoted for similar pyroclastic soils and weak rocks (Aversa and Evangelista, 1998; Esposito and Guadagno, 1998). Figure 2 shows the grain-size distribution determined on the samples of volcanic ash from Toledo corresponding to a sand with silt with a $d_{50} \cong 0.06 \mathrm{~mm}$ and a coefficient of uniformity $U \cong 20$. In the same figure, the range of grading quoted by Vinale (1988) for similar soils is also shown for comparison.

The tests were performed using a triaxial cell working under temperature controlled conditions, described in some detail by Cantone et al. (2006) and de Sanctis (2007). The experimental programme consisting of several tests on natural samples of both 

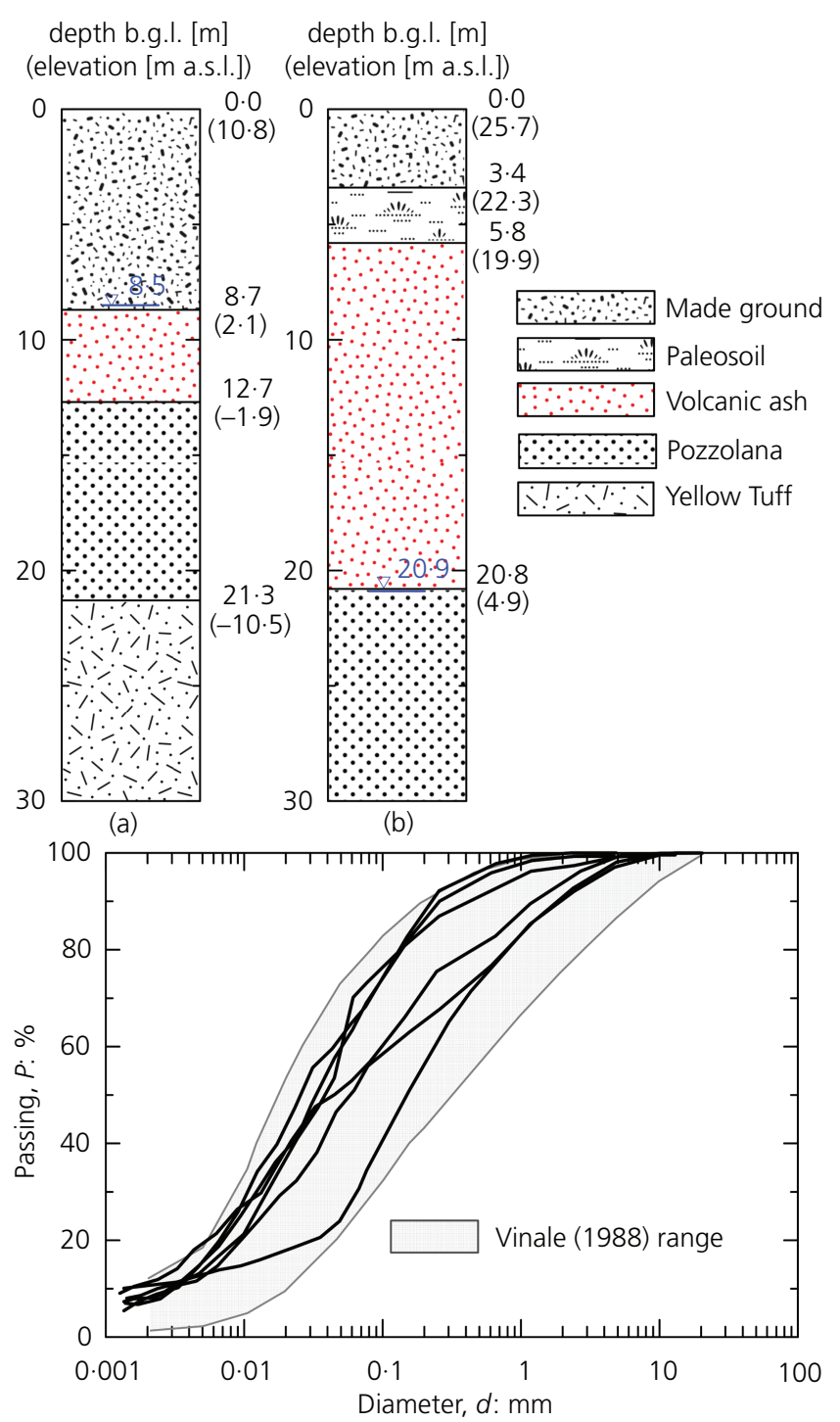

(c)

Figure 2. Soil profile at (a) Piazza Municipio and (b) Toledo sites. Grading of volcanic ash from Toledo site (c).

\begin{tabular}{lcccccc}
\hline$G_{S}$ & $\gamma: \mathrm{kN} / \mathrm{m}^{3}$ & $\gamma_{\mathrm{d}}: \mathrm{kN} / \mathrm{m}^{3}$ & $w / c: \%$ & $n: \%$ & e & S $_{\mathrm{r}:} \%$ \\
\hline 2.46 & 17.32 & 13.05 & 36.96 & 47.29 & 0.90 & 91.62
\end{tabular}

Table 1. Average physical properties of tested volcanic ash

volcanic ash and Neapolitan Yellow Tuff was carried out at different temperatures, confining stress and axial strain rates, as prescribed by the designers. Seven triaxial tests carried out on natural samples of volcanic ash at different temperatures and confining stress (see Table 2) were extracted to be examined in the present work.

Figure 3 shows the results of three triaxial compression tests carried out at room temperature, $T=20^{\circ} \mathrm{C}$, in terms of deviatoric stress-deviatoric strain $\left(\varepsilon_{s}: q\right)$ relationships and effective stress path $\left(p^{\prime}: q\right)$. The tests were carried out on fully saturated samples under drained conditions. The peak strength envelope

14. $q_{\mathrm{p}}=M_{\mathrm{p}} p^{\prime}+C_{\mathrm{p}}^{\prime}$

is also shown in Figure 3 as a dashed line. The peak strength envelope parameters for saturated unfrozen samples are obtained by linear best fit of the experimental data; the coefficient of correlation was $R^{2}=0 \cdot 99$. The parameters of the peak strength envelope are $M_{\mathrm{p}}=1 \cdot 3$ and $C_{\mathrm{p}}^{\prime}=20 \mathrm{kPa}$, corresponding to $\varphi_{\mathrm{p}}{ }^{\prime} \cong 33^{\circ}$ and $c_{\mathrm{p}}{ }^{\prime} \cong 10 \mathrm{kPa}$.

Figure 4 summarises the testing conditions in the triaxial tests on frozen samples in terms of followed mean total stress - temperature $(p: T)$, during the freezing stage, and mean total stress - deviatoric stress $(p: q)$ paths, during the shearing stage.

The main common phases of all tests were:

- initial drained isotropic compression to target mean effective stress $p^{\prime}(=200-350 \mathrm{kPa})$ using a back pressure $u=100 \mathrm{kPa}$;

- freezing to the target temperature $T\left(-6^{\circ} \mathrm{C}\right.$ or $\left.-10^{\circ} \mathrm{C}\right)$ over a period of about 6 hours, followed by an equalisation stage at constant temperature;

- shearing at controlled axial displacement rate $v_{\mathrm{p}}$ (0.06-0.006 $\mathrm{mm} / \mathrm{min})$.

Freezing of the sample was obtained by circulating a refrigerating fluid (glycol) in an inner cylinder surrounding the sample. Therefore, the freezing process proceeds from the external surface of the sample, where the target temperature is applied, towards the inside of the sample. During freezing, the drainage lines are open. However, as the pore water freezes, drainage is progressively inhibited.

During the shearing stages of three out of four tests, the temperature was increased from $-10^{\circ} \mathrm{C}$ to $-6^{\circ} \mathrm{C}$ (test TX1) and from $-6^{\circ} \mathrm{C}$ to $-4^{\circ} \mathrm{C}$ (tests TX3 and TX4), while the remaining sample was sheared to failure at a constant temperature of $-10^{\circ} \mathrm{C}$ (test TX2).

\section{Experimental results}

Figure 5 shows the results of the triaxial tests on frozen samples in terms of deviatoric stress against axial strain $\left(\varepsilon_{\mathrm{a}}: q\right)$ and temperature against axial strain $\left(\varepsilon_{\mathrm{a}}: T\right)$.

Both at a temperature of $-6^{\circ} \mathrm{C}$ and $-10^{\circ} \mathrm{C}$, the strength provided by the ice bonding prevails compared to that provided by the increasing confining stress; this is demonstrated by the fact that the peak deviatoric stress at $T=-6^{\circ} \mathrm{C}$ is about $1.75 \mathrm{MPa}$, irrespective of the confining pressure, and about $3.6 \mathrm{MPa}$ at $T=-10^{\circ} \mathrm{C}$, again irrespective of the confining pressure. Strictly, the results of the four triaxial tests on frozen samples cannot be compared directly, as tests TX1 and TX2, which were tested at $-10^{\circ} \mathrm{C}$, were also carried out using an axial strain rate one order of magnitude larger than that used in tests TX3 and TX4. For frozen 


\begin{tabular}{llccc}
\hline Name & \multicolumn{1}{c}{ Type } & Temperature $T:{ }^{\circ} \mathrm{C}$ & $\begin{array}{c}\text { Confining } \\
\text { stress } p^{\prime}{ }^{\prime} \text { : } \mathrm{kPa}\end{array}$ & $\begin{array}{c}\text { Axial displacement } \\
\text { rate } \mathrm{V}_{\mathrm{a}}: \mathrm{mm} / \mathrm{min}\end{array}$ \\
\hline TX1_sat & $\begin{array}{l}\text { drained triaxial } \\
\text { compression } \\
\text { TX2_sat }\end{array}$ & 20 & 50 & 0.006 \\
& $\begin{array}{l}\text { drained triaxial } \\
\text { compression }\end{array}$ & 20 & 100 & 0.006 \\
TX3_sat & $\begin{array}{l}\text { drained triaxial } \\
\text { compression }\end{array}$ & 20 & 150 & 0.006 \\
TX1 & triaxial compression & -10 & 200 & 0.06 \\
TX2 & triaxial compression & -10 & 350 & 0.06 \\
TX3 & triaxial compression & -6 & 200 & 0.006 \\
TX4 & triaxial compression & -6 & 350 & 0.006
\end{tabular}

Table 2. Tests examined in the present work

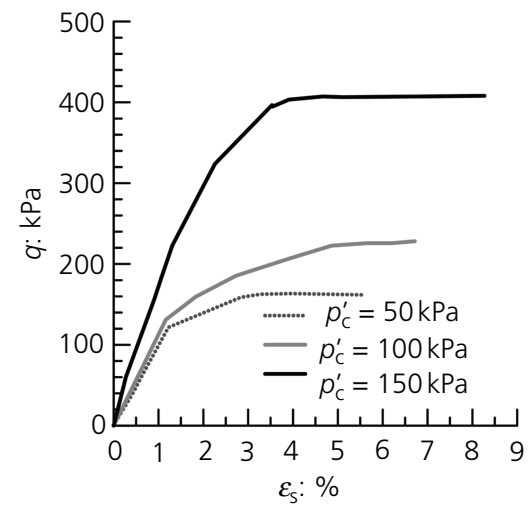

(a)

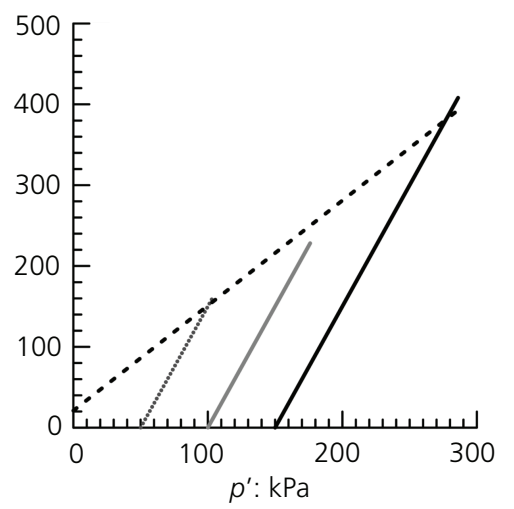

(b)

Figure 3. Triaxial tests results at $T=20^{\circ} \mathrm{C}$ in saturated condition:

(a) $\varepsilon_{s}: q$ plane; (b) $p^{\prime}: q$ plane

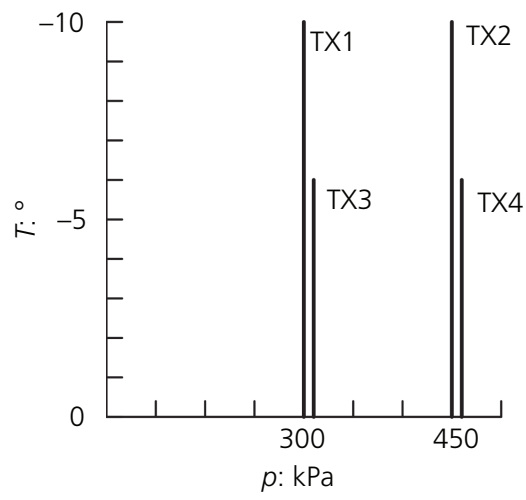

(a)

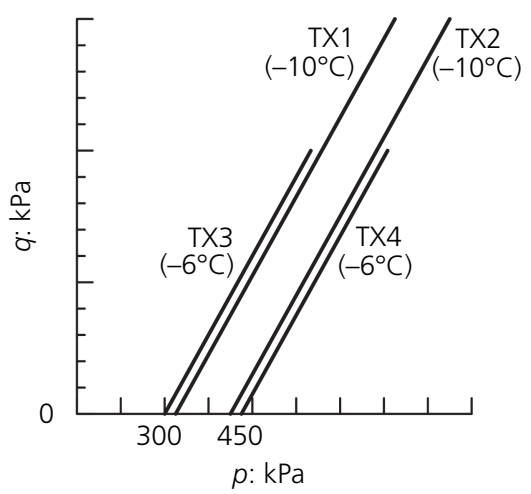

(b)

Figure 4. Paths followed in triaxial tests on frozen samples:

(a) freezing stage: mean total stress $p$ - temperature $T$;

(b) shearing stage: mean total stress $p$ - deviatoric stress $q$ 


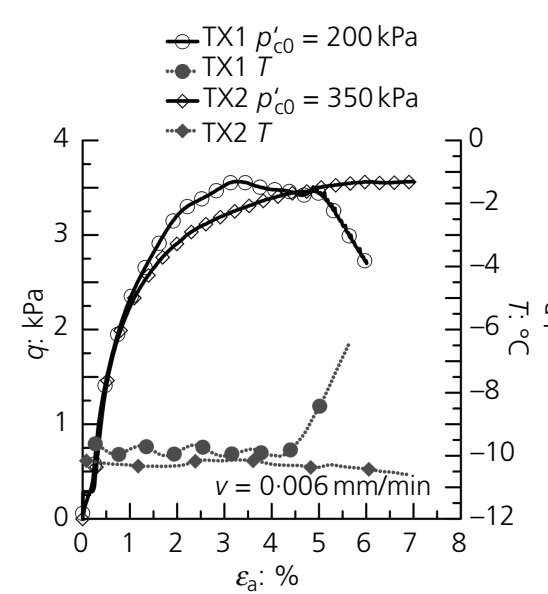

(a)

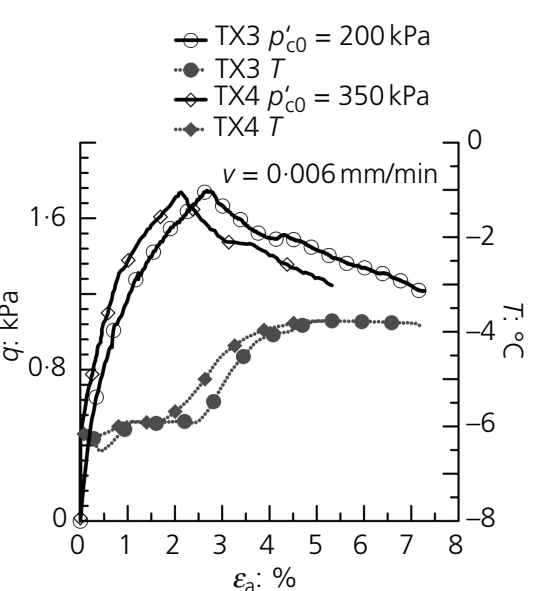

(b)

Figure 5. Results of triaxial compression on frozen samples:

(a) TX1 and TX2 T=-10 $\div-6^{\circ} \mathrm{C}$; (b) TX3 and TX4 $T=-6-{ }^{\circ} \mathrm{C} \div-4^{\circ} \mathrm{C}$

soils, both factors, namely a lower temperature and a larger axial strain rate, concur to an increased strength. However, because of its direct influence on the strength of intergranular ice and on the amount of unfrozen water in a frozen soil, temperature plays a main role in determining the mechanical behaviour of the frozen samples. This is clearly shown by the results given in Figure 5 , as the increase of temperature during the shearing stages of tests TX1, TX3 and TX4 causes softening, with a decrease of deviatoric stress to about $1.2 \mathrm{MPa}$ for tests TX3 and TX4, and to about $2 \cdot 5 \mathrm{MPa}$ for test TX1.

The overall results obtained from triaxial compression tests on natural and frozen samples are summarised in Figure 6 in terms of deviatoric stress $q$ against initial mean effective stress $p^{\prime}{ }_{\mathrm{c} 0}$.

\section{Numerical work}

\section{Model calibration}

Literature data, obtained by Nicotera (1998) and Picarelli et al. (2007) on volcanic ash retrieved from the subsoil of Napoli, were used to calibrate the following parts of the constitutive model:

- water retention curve, linking the degree of saturation $S_{1}=V_{\mathrm{w}} /$ $V_{\mathrm{v}}$ to suction $s$ (Equation 2);

- Normal compression line (NCL), with particular reference to the evolution of its slope $\lambda$ with suction $s$ (Equation 8 );

- LC curve, linking the evolution of the pre-consolidation stress $p_{\mathrm{n} 0}$ with suction (Equation 7).

Figure 7 shows a comparison between the experimental water retention curve obtained from measurements in the pressure plate apparatus and in oedometer tests under suction-controlled conditions together with the van Genuchten (1980) model. To obtain the corresponding freezing retention model, the ice entry value $P$ was evaluated from the air entry value $P_{\mathrm{a}}$ as $P=P_{\mathrm{a}} \cdot \sigma_{\mathrm{l}} / \sigma_{\mathrm{la}}$,

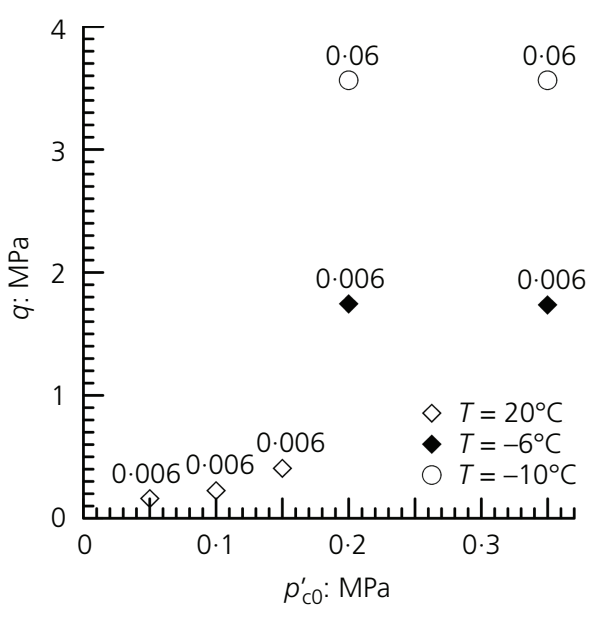

Figure 6. Overall results in unfrozen and frozen conditions in terms of peak deviatoric stress $q$ against initial confining stress $p_{c 0}^{\prime}$ (labelled displacement rate)

where $\sigma_{\mathrm{la}}=0.072 \mathrm{~N} / \mathrm{m}$ and $\sigma_{\mathrm{li}}=0.033 \mathrm{~N} / \mathrm{m}$ are the liquid-air and liquid-ice surface tensions at $T=20^{\circ} \mathrm{C}$. Table 3 summarises the parameters adopted for the freezing retention model.

The slope of the NCL $\lambda(\mathrm{s})$ was obtained from the results of onedimensional compression tests carried out under suction controlled conditions, while the slope of the unloading-reloading lines $\kappa(\mathrm{s})$ was taken to be constant with suction $\kappa=0 \cdot 02$. The same set of data was used to obtain the evolution of the pre-consolidation stress with suction $p_{\mathrm{n} 0}(\mathrm{~s})$. Figure 8 shows a comparison between the experimental data used to calibrate the model and the model predictions for $\lambda(\mathrm{s})$ and $p_{\mathrm{n} 0}(\mathrm{~s})$.

The value of $M$ in Equation 7 was obtained from the triaxial tests on unfrozen soil $M=M_{\mathrm{p}}=1 \cdot 3$, while the remaining parameters of 


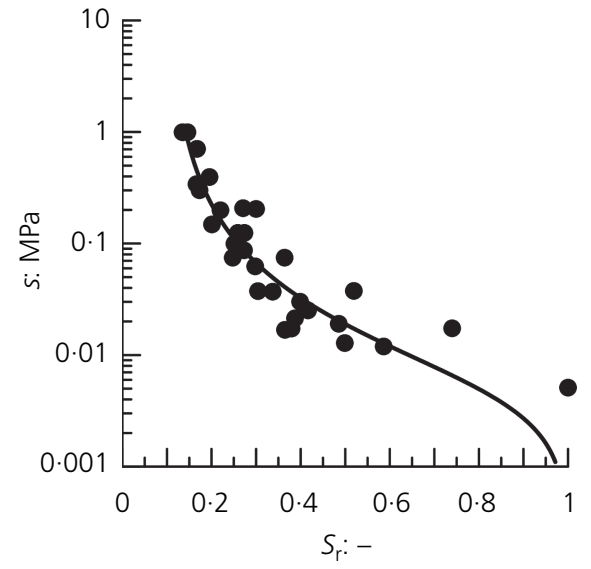

Figure 7. BBM parameters comparison between experimental data (Nicotera, 1998) and model predictions: (a) slope of NCL $\lambda$ with suction s; (b) LC curve

\begin{tabular}{lccc}
\hline$P_{\mathrm{a}}: \mathrm{kPa}$ & $m$ & $K_{\text {sat: }}: \mathrm{m} / \mathrm{s}$ & $P: \mathrm{kPa}$ \\
\hline 5 & 0.366 & $10^{-6}$ & 10
\end{tabular}

Table 3. Freezing retention model: adopted parameters

the mechanical model, namely the shear modulus $G$ and parameter $k$, defining the increase of $p_{\mathrm{s}}$ with suction, Equation 10 , and the viscous parameters $\Gamma_{0}$ and $\delta$ were obtained by direct calibration against the experimental data discussed below. Table 4 summarises the parameters adopted for the mechanical model.

The thermal conductivity of the soil $k_{\mathrm{t}}$ depends on the volume fractions and conductivities of the soil mineral phase $k_{\mathrm{ts}}$ of the liquid (unfrozen) water phase $k_{\mathrm{t}}$, and, in the case of frozen ground, of the ice (solid) water phase $k_{\mathrm{ti}}$. Assuming saturated ground, the overall thermal conductivity calculated by using a weighted average (Côté and Konrad, 2005)

15. $k_{\mathrm{t}}=k_{\mathrm{ts}}^{(1-n)} \cdot k_{\mathrm{tl}}^{S_{\mathrm{l}} n} \cdot k_{\mathrm{ti}}^{\left(1-S_{\mathrm{l}}\right) n}$

where $n$ is the porosity of the soil. Although the thermal conductivities of liquid water and ice depend slightly on temperature (Farouki, 1982; Frivik, 1981), in this study, average constant values were considered over the whole range of temperatures examined in this study $\left(-10^{\circ} \mathrm{C}\right.$ to $\left.25^{\circ} \mathrm{C}\right)$. This introduces a maximum error on the conductivity of water of about $9 \%$ and a maximum error on the conductivity of ice of only $2 \%$. The value of the thermal conductivity of the volcanic ash was obtained by back analysing the behaviour observed on a trial site at Piazza Municipio, including several vertical freezing tubes and observation holes for the measurement of ground temperatures in cycles of freezing and thawing (de Sanctis, 2006, 2007). The adopted values of thermal conductivities of the individual components are reported in Table 5.

\section{Numerical analyses}

The THM numerical analyses of the triaxial tests were performed under axi-symmetric conditions. Taking advantage of symmetry, only one quarter of the sample was modelled using the finite-element mesh shown in Figure 9, consisting of 72 quadratic linear elements. Temperature was applied as a boundary condition at the top and right border of the mesh, while, during axial loading, a constant axial displacement rate was applied at the top boundary. The initial pore water pressure was set to $p_{\mathrm{w} 0}=0 \mathrm{kPa}$ as the hydrostatic increment of pore water pressure along the sample was neglected due to the small dimensions of the sample; drainage was allowed from the top border. The initial stress was set equal to the effective confining stress, and at the right border, the boundary stress was maintained equal to the effective confining stress for the entire simulation.

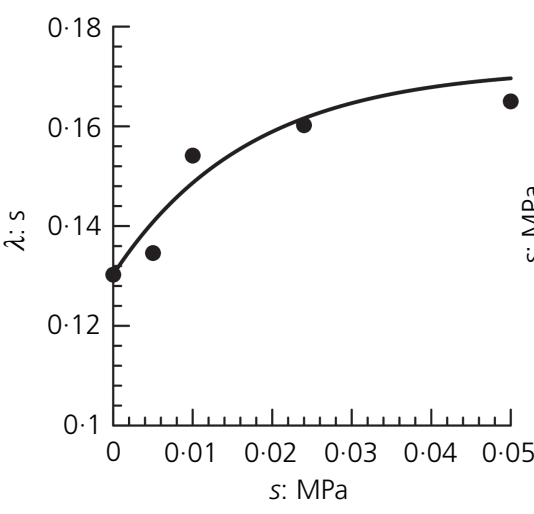

(a)

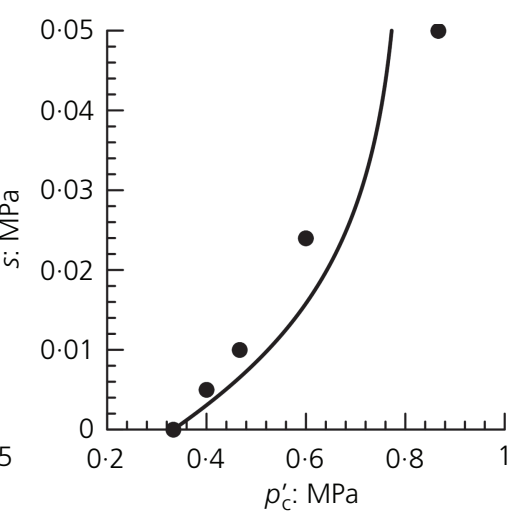

(b)

Figure 8. Water retention curve for volcanic ash: comparison between experimental data (Nicotera, 1998) and model predictions 


\begin{tabular}{ccccccccccc}
$\Gamma_{0}: \mathrm{s}^{-1}$ & $N$ & $\delta$ & $\kappa$ & $\lambda(0)$ & $r$ & $\beta$ & $p^{c:} \mathrm{MPa}$ & $k$ & $M$ & G: MPa \\
\hline $10^{-7}$ & 3 & 0 & 0.02 & 0.13 & 1.3 & 58 & 10 & 1.2 & 1.3 & 40
\end{tabular}

Table 4. Visco-plastic mechanical model: adopted parameters

\begin{tabular}{lcc}
\hline$k_{\mathrm{ts}}: \mathrm{W} / \mathrm{mK}$ & $k_{\mathrm{tw}: \mathrm{W} / \mathrm{mK}}$ & $k_{\mathrm{ti}}: \mathrm{W} / \mathrm{mK}$ \\
\hline 3.0 & 0.6 & $2 \cdot 2$
\end{tabular}

Table 5. Thermal conductivities of mineral, liquid water and ice

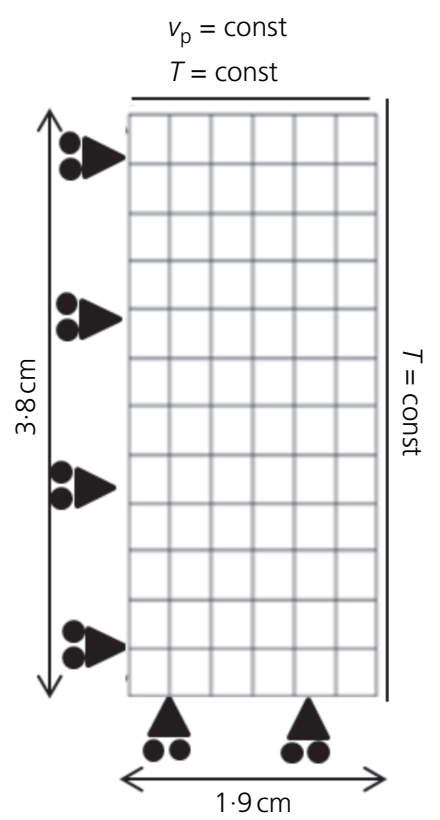

Figure 9. Finite-element mesh and boundary conditions adopted in the analyses

The main phases of the numerical simulations were

- definition of the initial state of stress, with $\sigma_{\mathrm{x}}=\sigma_{\mathrm{y}}=p_{\mathrm{c} 0}$, the initial temperature $T_{0}=25^{\circ} \mathrm{C}$, a back pressure $p_{\mathrm{w} 0}=0 \mathrm{kPa}$ and a constant porosity $n=0 \cdot 50$;

- application of a ramp of decreasing temperature, from $25^{\circ} \mathrm{C}$ to $-10^{\circ} \mathrm{C}$ or $-6^{\circ} \mathrm{C}$, at the right and top border both free to move during freezing;

- maintenance of temperature to equilibrium;

- where applicable, application of a ramp of increasing temperature, from $-10^{\circ} \mathrm{C}$ to $-6^{\circ} \mathrm{C}$ or from $-6^{\circ} \mathrm{C}$ to $-4^{\circ} \mathrm{C}$, at the right and top border during shearing;

- axial loading under controlled displacement rate, $v_{\mathrm{a}}=0.06 \mathrm{~mm} /$ $\min$ or $0.006 \mathrm{~mm} / \mathrm{min}$, of the top boundary of the mesh.

\section{Model prediction}

The THM analyses were performed to obtain the remaining parameters of the model and test its ability to reproduce the observed behaviour under different temperatures and mean confining stress. The predictions of the model during the freezing stage of tests TX3 are reported in Figure 10 in terms of contours of temperature $T$, liquid water pressure $P_{1}$, porosity $n$ and degree of saturation $S_{1}$ at a specific time $(t=15 \mathrm{~h})$.

The model predicts that the freezing front advances from the boundary of the sample towards its centre, with a gradient $\Delta T /$ $\Delta x \approx-1 \cdot 0 / 0 \cdot 019(\% / \mathrm{m})$, see Figure 10(a). Due to the decreasing temperature, the liquid water pressure becomes negative where the freezing front advances, see Figure 10(b). Also, in the frozen area, there is a marked increase of porosity induced by phase transformation (from water to ice) coupled with the changes of liquid water pressure, see Figure 10(c), and a corresponding decrease of liquid water saturation, see Figure 10(d).

Figure 11 shows the profiles of the main physical quantities computed at a distance of $9.5 \mathrm{~mm}$ from the sample axis, in five stages of the simulation of test TX1, namely before (initial), during and at the end of freezing, during shearing at constant temperature and at the end of the simulation, after thawing.

During the freezing stage, as temperature decreases (Figure 11(a)), the liquid water pressure decreases (Figure 11(b)), and the ice pressure increases (Figure 11(c)). The net stress acting on the soil skeleton decreases (see Equation 5), with the consequence that the porosity of the soil increases (Figure 11(d)).

Suction is initially zero everywhere in the sample (Figure 11(e)); during freezing, it increases starting from the top border, where it is maximum; at the end of freezing and during shearing at constant temperature, suction is constant, $s \cong 12 \mathrm{MPa}$, and then decreases on thawing, again starting from the top border and then towards the centre of the sample.

The degree of saturation of liquid water $S_{1}$ decreases drastically (Figure 11(f)) right from the beginning of the freezing stage; this is due to the freezing retention model of the volcanic ash, which is characterised by a low ice entry value and a sudden reduction of the degree of saturation of liquid water as suction increases.

Figure 12 shows a comparison between the observed and predicted stress-strain behaviour during the axial compression stage of tests TX1, TX2, TX3 and TX4. The agreement between model predictions and experimental data is quite satisfactory both for samples tested at the same temperature with two different confining stresses and for those tested at the same confining stress at two different temperatures. As observed in the experimental tests, the predicted strength of the two samples tested at $T=-10^{\circ} \mathrm{C}$ is the same, irrespective of the confining pressure. The mechanical behaviour predicted by the model is slightly stiffer than observed, and thus, the final strength is reached at strains in the order of $1 \%$ in all tests, while in the two triaxial tests carried out at $-10^{\circ} \mathrm{C}$ (TX1 


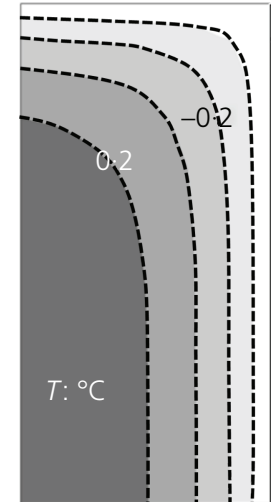

(a)

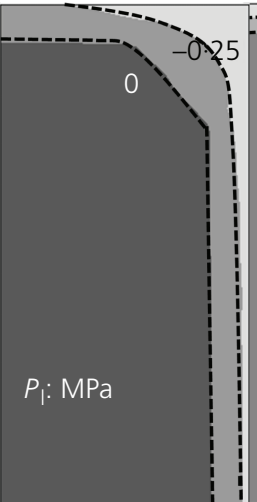

(b)

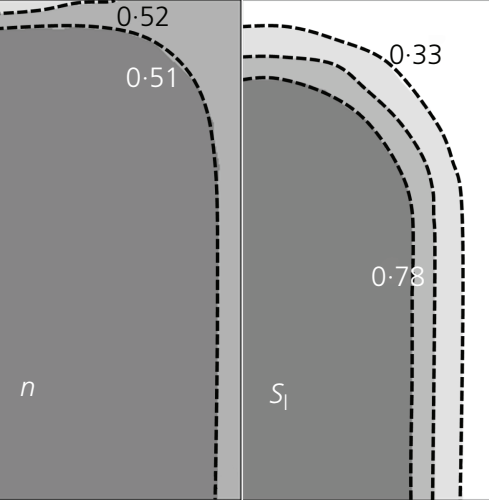

(c)

(d)

Figure 10. Test TX1 - predicted contours of (a) temperature $T$,

(b) liquid water pressure $P_{1}$, (c) porosity $n$ and (d) degree of saturation of liquid water $S_{1}$ during freezing

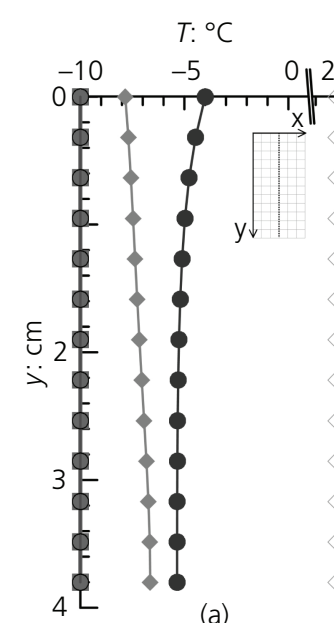

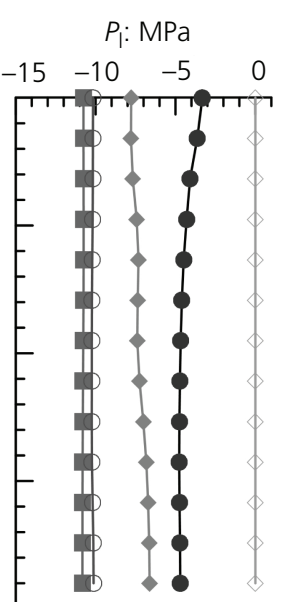

(b)

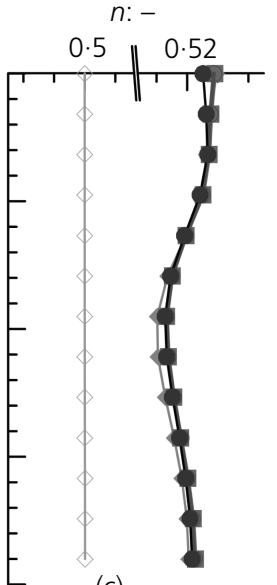

(c)

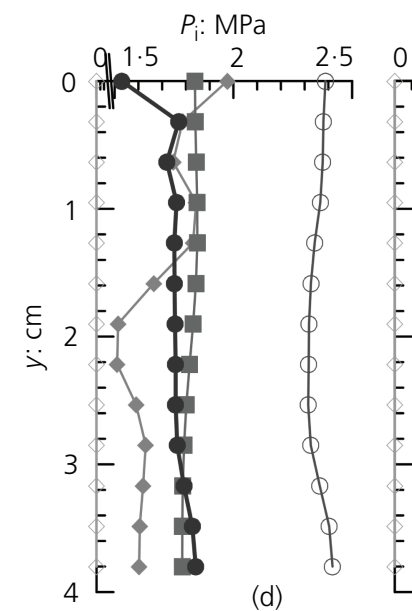

(d) $s=P_{\mathrm{i}}-P_{\mathrm{i}}: \mathrm{MPa}$

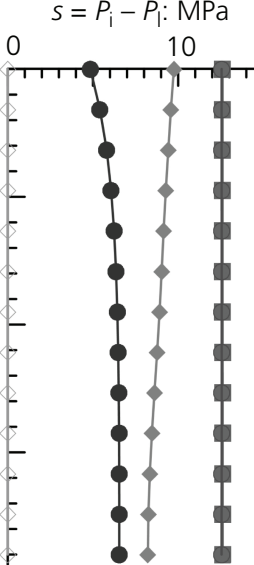

(e) S: -

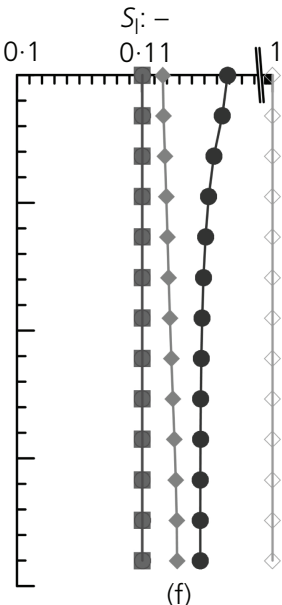

(f)

$\neg$ Initial $\rightarrow$-Ramp to $-10^{\circ} \mathrm{C}-$-Freezing $-10^{\circ} \mathrm{C}$ - Loading $-10^{\circ} \mathrm{C}-$-Thawing $-6.5^{\circ} \mathrm{C}$

Figure 11. Numerical analysis of test TX1 - computed profiles of (a) temperature $T$, (b) liquid water pressure $P_{1},(c)$ porosity $n,(d)$ ice pressure $P_{\mathrm{i}}$, (e) suction $s$ and $(\mathrm{f})$ degree of saturation of liquid water $S$ at a distance $x=9.5 \mathrm{~mm}$ in different stages of the simulation 


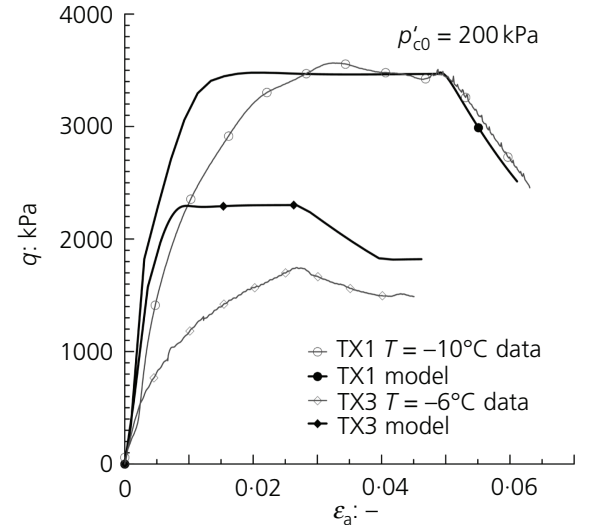

(a)

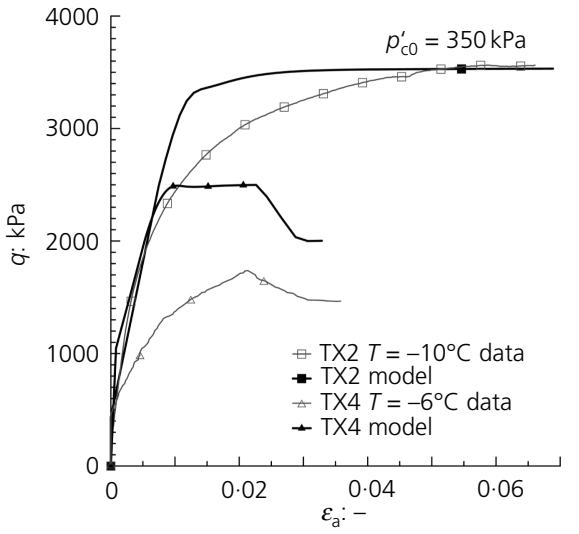

(b)

Figure 12. Measured and predicted stress strain behaviour in triaxial compression

and TX2), the maximum deviatoric strength was attained at axial strains $\varepsilon_{\mathrm{a}}=5 \%$. On the other hand, in the two tests carried out at $T=-6^{\circ} \mathrm{C}$ (TX3 and TX4), thawing started well before the shear strength had been attained, at axial strains of about $2 \%$ to $2 \cdot 5 \%$, where the model had already reached peak strength, while the samples were still hardening to failure. It is reasonable to assume that, if the shearing stage of tests TX3 and TX4 had been continuing at constant temperature, the deviatoric stress would have reached values similar to those predicted by the model. The softening behaviour on thawing is remarkably well reproduced by the model for all tests.

\section{Conclusions}

AGF is one of the construction techniques that were extensively adopted to excavate the station tunnels and the inclined passageways through loose granular soils and the fractured soft rock below the ground water table during the construction of Line 1 of Napoli underground. Recent advances in multiphase soils mechanics provide a consistent framework for understanding the engineering behaviour of such artificial frozen soils. Built on those developments, an international cooperation has been established bringing together laboratory work, constitutive modelling and field data involving UPC Barcelona, Università di Roma Tor Vergata and technical personnel and engineers involved in the design and construction of Napoli underground.

The experiment results on a volcanic ash retrieved during construction of Napoli underground at different temperatures, confining stress and rates of loading were presented. In general, a decrease in temperature induces an increase in the strength of frozen samples as well as an increase in the rate of loading increases the strength of soil. In the range of investigated confining stress, the effect of temperature is predominant compared with the effect of confining stress, as the samples tested at the same temperature exhibited the same strength irrespective of the confining stress.
A fully coupled THM model developed to consider a variety of geotechnical processes involving freezing and thawing has been validated and calibrated. The constitutive model adopted includes a critical state mechanical constitutive model that adopts total stress, liquid pressure and ice pressure model reducing to an effective stress-based model similar to the Modified Cam-Clay model under unfrozen conditions. The constitutive relations were implemented in the visco-plastic form although used as a regularising procedure has been useful to model the behaviour of frozen samples. The performance of the model is quite satisfactory during freezing, axial loading in frozen conditions and thawing.

Further experiments at different temperatures and the same rate of loading are required to investigate the viscous behaviour of frozen volcanic ash. To this purpose, modifications to the temperaturecontrolled triaxial equipment that will permit to measure the volume strains of frozen soil and to change the freezing mechanism so that the freezing front will proceed from the centre of the sample towards its boundaries will be implemented. From the point of view of constitutive modelling, modifications to the present formulation are being examined to describe better the viscous behaviour of the frozen soil, mechanical degradation on cycles of freezing and thawing and the adoption of the Bishop stress as a constitutive variable.

\section{Acknowledgements}

The financial support of the European Commission for the first author through the 'Marie Curie Intra European Fellowship' (EU FP7-NuMAGF, grant agreement 272073) is acknowledged. The authors are grateful to Studio Cavuoto, Tecno-in SpA and professor Alessandro Mandolini for their technical support as well as their permission to publish research results.

\section{REFERENCES}

Alonso EE, Gens A and Josa A (1990) A constitutive model for partially saturated soils. Géotechnique 40(3): 405-430. 
Alonso EE, Olivella S and Pinyol NM (2005) A review of Beliche Dam. Géotechnique 55(4): 267-285.

Andersland OB and Ladanyi B (2004) Frozen Ground Engineering. Wiley and Sons Inc., New Jersey.

Aversa S and Evangelista A (1998) The mechanical behaviour of a pyroclastic rock: yield strength and destructuration effects. Rock Mech. Rock Eng. 31(1): 25-42.

Cantone A, De Sanctis L and Mandolini A (2006) Interventi di protezione degli scavi di gallerie mediante congelamento. Attività sperimentali nella Stazione Muncipio della Metropolitana di Napoli. Incontro Annuale dei Ricercatori $d i$ Geotecnica, Pisa, Italy.

Casini F, Gens A, Olivella S and Viggiani GMB (2013) Coupled phenomena induced by freezing in a granular material. Coupled Phenomena in Environmental Geotechnics: From Theoretical and Experimental Research to Practical Applications - Proceedings of the International Symposium, ISSMGE TC 215, Torino, Italy, pp. 467-473.

Cavuoto F, Corbo A, Fico R, De Risi A and Giannelli F (2011) La metropolitana di Napoli: la galleria di scavalco della stazione Toledo. Confronto tra misure dei cedimenti e analisi numeriche. XXIV Convegno Nazionale di Geotecnica, Napoli, Italy, pp. 1-9.

Colombo G (2010) Il congelamento artificiale del terreno negli scavi della metropolitana di Napoli. Rivista Italiana di Geotecnica XLIV(4): 42-62.

Conti R, Tamagnini C and DeSimone A (2013) Critical softening in Cam-Clay plasticity: adaptive viscous regularization, dilated time and numerical integration across stress-strain jump discontinuities. Comput. Methods Appl. Mech. Engrg. 258: 118-133.

Côté J and Konrad JM (2005) A generalized thermal conductivity model for soils and construction materials. Can. Geotech. J. 42(2): 443-458.

Desai CS and Zhang D (1987) Viscoplastic model for geologic materials with generalized flow rule. Int. J. Num. An. Meth. Geomech. 11: 603-620.

de Sanctis L (2006) Interpretazione del campo sperimentale predisposto per gli interventi di congelamento nella stazione Municipio. Rapporto di Ricerca, Consorzio Icotekne 1(1): 1-97.

de Sanctis L (2007) Protezione degli scavi di gallerie mediante congelamento. Rapporto tecnico, Consorzio Ikotekne 2(1): 1-97.

De Santis D (2006) Osservazione Sperimentale e Analisi Numerica Degli Interventi di Protezione Dello Scavo con AGF. Master thesis, Università di Roma Tor Vergata, Rome, Italy (in Italian).

Esposito L and Guadagno FM (1998) Some special geotechnical properties of pumice deposits. Bull. Eng. Geol. Environ. 57: 41-50.

Farouki O (1982) Evaluation of methods for calculating soil thermal conductivity. US Army Corps of Engineers Report, Cold Regions Research \& Engineering Laboratory, Hanover, N.H.
Frivik PE (1981) State-of-the-art report. Ground freezing: thermal properties, modelling of processes and thermal design. Engineering Geology 12: 115-133.

Gens A (2010) Soil-environment interactions in geotechnical engineering. Géotechnique 60(1): 3-74.

Gens A, Garcia-Molina AJ, Olivella S, Alonso EE and Huertas F (1998) Analysis of a full scale in situ test simulating repository conditions. Int. J. Numer. Anal. Methods Geomech. 22(7): $515-548$.

Harris JS (1995) Ground Freezing in Practice. Thomas Teldford Ltd, London.

Molist J (1997) Extension of the VP Model by Desai to Unsaturated Soils. Graduation thesis, Universitat Politecnica de Catalunya, Barcelona, Spain, www.upc.edu.

Morgenstern NR, Roggensack WD and Weaver JS (1980) The behaviour of friction piles in ice and ice-rich soils. Can. Geotech. J. 17(3): 405-415.

Mualem Y (1976) A new model for predicting the hydraulic conductivity of unsaturated porous media. Water Resources Research 12(3): 513-522.

Nicotera MV (1998) Effetti del Grado di Saturazione Sul Comportamento di Una Pozzolana del Napoletano. PhD thesis, Università di Napoli Federico II, Napoli, Italy (in Italian).

Nishimura S, Gens A, Olivella S and Jardine RJ (2009) THMcoupled finite element analysis of frozen soil: formulation and application. Géotechnique 59(3): 159-171.

Olivella S, Carrera J, Gens A and Alonso EE (1994) Nonisothermal multiphase flow of brine and gas through saline media. Transp. Porous Media 15(3): 271-293.

Olivella S, Gens A, Carrera J and Alonso EE (1996) Numerical formulation for a simulator 'CODE_BRIGHT' for the coupled analysis of saline media. Engng. Comput. 13(7): 87-112.

Papakonstantinou S, Anagnostou G and Pimentel E (2012) Evaluation of ground freezing data from the Naples subway. Proceedings of the ICE: Geotechnical Engineering. http://dx.doi.org/10.1680/geng.10.00099.

Perzyna P (1986) Fundamental problems in viscoplasticity. Advances in Applied Mechanics. Academic Press, New York, vol. 9, pp. 244-368.

Picarelli L, Evangelista A, Rolandi G et al. (2007) Mechanical properties of pyroclastic soils in Campania Region. 1st International Workshop on Characterisation and Engineering Properties of Natural Soils, Singapore 3-4: 2331-2383.

Russo G, Viggiani C and Viggiani GMB (2012) Geotechnical design and construction issues for lines 1 and 6 of the Naples underground. Geomechanik und Tunnelbau 5(3): 300-311.

Sanchez M (1997) Implementation of VP Model by Desai in CB Used to Simulate Triaxial Tests Under Drained Conditions. Master thesis, Universitat Politecnica de Catalunya, Barcelona, Spain, www.upc.edu.

Sanger FJ and Sayles FH (1979) Thermal and rheological computations for artificially frozen ground construction. Engineering Geology 13: 311-337. 
Sayles FH (1968) Creep of Frozen Sands. U.S. Army Cold Regions Research and Engineering Laboratory Technical Report 190.

Studio Cavuoto Engineering Service, Naples, Italy, www. studiocavuoto.com.

Tecno In Engineering Services, Naples, Italy, www.tecnoin.it/en/. van Genuchten MTh (1980) A closed-form equation for predicting the hydraulic conductivity of unsaturated soils. Soil Sci. Soc. Am. J. 44: 892-898.

Viggiani GMB and de Sanctis L (2009) Geotechnical aspects of underground railway construction in the urban environment: the examples of Rome and Naples. Geological Society Engineering Geology Special Publication 22(1): 215-240.
Vinale F (1988) Caratterizzazione del sottosuolo di un'area campione di napoli ai fini di una microzonazione sismica. Rivista Italiana di Geotecnica 3: 141-162.

Wang W, Sluys L and de Borst R (1997) Viscoplasticity for instabilities due to strain softening and strain-rate softening. Int. J. Numer. Anal. Meth. Geomech. 40: 3839-3864.

Zhou MM and Meschke G (2013) A three-phase thermo-hydromechanical finite element model for freezing soils. Int. J. Numer. Anal. Meth. Geomech. 37(18): 3173-3193.

Zienkiewicz OC and Taylor RL (2000) The Finite Element Method: The Basis, 1, Butterworth-Heinemann, 689 pp. 